\title{
Ação antimicrobiana dos compostos voláteis do óleo essencial das folhas secas de
}

\section{Croton blanchetianus Baill}

\author{
Antimicrobial action of volatile compounds in essential oil from dry leaves of Croton blanchetianus \\ Baill
}

Acción antimicrobiana de compuestos volátiles en aceite esencial de hojas secas de Croton

blanchetianus Baill

Recebido: 15/12/2021 | Revisado: 24/12/2021 | Aceito: 29/12/2021 | Publicado: 06/01/2022

Elayne Cardoso de Vasconcelos

ORCID: https://orcid.org/0000-0001-6291-9096

Universidade Federal de Santa Catarina, Brasil Instituto Federal do Ceará, Brasil

E-mail: elayne@ifce.edu.br

Camila Casagrande Paganini

ORCID: https://orcid.org/0000-0002-1776-1661 Universidade Federal de Santa Catarina, Brasil E-mail: camilacpaganini@gmail.com

Evânia Altina Teixeira de Figueiredo ORCID: https://orcid.org/0000-0001-9209-0477 Universidade Federal do Ceará, Brasil E-mail evanialtina@gmail.com

Gláucia Maria Falcão de Aragão ORCID: https://orcid.org/0000-0002-7553-8919 Universidade Federal de Santa Catarina, Brasil E-mail: gmf.aragao@gmail.com

\begin{abstract}
Resumo
O Croton blachetianus, popularmente denominado marmeleiro, é um arbusto rico em metabólitos secundários que apresenta diversas atividades biológicas. O objetivo desse estudo foi determinar a composição dos compostos voláteis do óleo essencial das folhas secas de C. blanchetianus e sua ação antimicrobiana (dose mínima inibitória - DMI do vapor) sobre as cepas das bactérias ácido-lácticas (BAL), Weissella viridescens e Leuconostoc mesenteroides, deteriorantes de produtos cárneos. O óleo essencial das folhas secas de C. blanchetianus foi extraído pela técnica de hidrodestilação e os compostos voláteis foram analisados pela técnica de headspace, por cromatografia gasosa. A dose mínima inibitória na fase vapor foi definida como a dose mínima de solução de óleo essencial de C. blanchetianus em DMSO 5\% cujo vapor inibe completamente o crescimento das BAL, durante 48 horas. Posteriormente, o efeito bactericida e bacteriostático foi determinado. Os compostos majoritários encontrados foram os terpenos eucaliptol $(32,94 \%)$ e D- $\alpha$-Pineno $(29,43 \%)$. A dose mínima inibitória foi de $0,32 \mathrm{~g} / \mathrm{mL}$, para ambos os microrganismos. $\mathrm{O}$ efeito bactericida para $W$. viridescens foi observado pela ação do vapor da solução de $0,32 \mathrm{~g} / \mathrm{mL}$ e, para a L. mesenteroides, o efeito bacteriostático e bactericida foi pela ação do vapor da solução de $0,40 \mathrm{~g} / \mathrm{mL}$ e $0,57 \mathrm{~g} / \mathrm{mL}$, respectivamente. Assim, foi possível observar a presença de terpenos como compostos majoritários na análise por headspace, bem como a atividade antimicrobiana, bacteriostática e bactericida do óleo essencial das folhas secas de C. blanchetianus frente as BAL $W$. viridescens e $L$. mesenteroides.
\end{abstract}

Palavras-chave: Headspace; Antimicrobiano; Bacteriostático; Bactericida.

\begin{abstract}
Croton blachetianus, popularly called marmeleiro, is a shrub rich in secondary metabolites that has several biological activities. The aim of this study was to determine the composition of volatile compounds in the essential oil of dry leaves of $C$. blanchetianus and its antimicrobial action (minimum inhibitory dose - vapor DMI) on lactic acid bacteria (LAB), Weissella viridescens and Leuconostoc mesenteroides, spoilage bacteria for meat products. The essential oil from the dry leaves of $C$. blanchetianus was extracted by the hydrodistillation technique and the volatile compounds were analyzed by CG headspace technique. The minimum inhibitory dose in the vapor phase was defined as the minimum dose of an essential oil solution of C. blanchetianus in 5\% DMSO whose vapor completely inhibits BAL's growth for 48 hours. Subsequently, the bactericidal and bacteriostatic effect was determined. The major compounds found were eucalyptol (32.94\%) and D- $\alpha$-Pinene (29.43\%) terpenes. The minimum inhibitory dose was $0.32 \mathrm{~g} / \mathrm{mL}$ for
\end{abstract}


both microorganisms. The bactericidal effect for $W$. viridescens was observed by the action of vapor from the 0.32 $\mathrm{g} / \mathrm{mL}$ solution and for $L$. mesenteroides the bacteriostatic and bactericidal effect was observed by the action of vapor from the $0.40 \mathrm{~g} / \mathrm{mL}$ and 0.57 solution $\mathrm{g} / \mathrm{ml}$, respectively. Thus, it was possible to observe the presence of terpenes, as major compounds in the headspace analysis, as well as the antimicrobial, bacteriostatic and bactericidal activity of the essential oil from dry leaves of $C$. blanchetianus against BAL W. viridescens and L. mesenteroides.

Keywords: Headspace; Antimicrobial; Bacteriostatic; Bactericide.

\section{Resumen}

Croton blachetianus, popularmente llamado marmeleiro, es un arbusto rico en metabolitos secundarios que tiene varias actividades biológicas. El objetivo de este estudio fue determinar la composición de compuestos volátiles en el aceite esencial de hojas secas de $C$. blanchetianus y su acción antimicrobiana (dosis mínima inhibitoria - DMI de vapor) sobre bacterias ácido lácticas (BAL), cepas Weissella viridescens y de Leuconostoc mesenteroides, deterioro de productos cárnicos. El aceite esencial de las hojas secas de $C$. blanchetianus se extrajo mediante la técnica de hidrodestilación y los compuestos volátiles se analizaron mediante la técnica de headspace, mediante cromatografía de gases. La DMI en la fase de vapor se definió como la dosis mínima de una solución de aceite esencial de $C$. blanchetianus en DMSO al 5\% cuyo vapor inhibe completamente el crecimiento de BAL durante 48 horas. Posteriormente, se determinó el efecto bactericida y bacteriostático. Los principales compuestos encontrados fueron eucaliptol (32.94\%) y terpenos D- $\alpha$-Pineno (29.43\%). La DMI fue de $0.32 \mathrm{~g} / \mathrm{mL}$ para ambos microorganismos. El efecto bactericida para $W$. viridescens se observó por la acción del vapor de la solución $0.32 \mathrm{~g} / \mathrm{mL}$ y para $L$. mesenteroides el efecto bacteriostático y bactericida se observó por la acción del vapor de la solución $0.40 \mathrm{~g} / \mathrm{mL}$ y $0.57 \mathrm{~g} / \mathrm{ml}$, respectivamente. Así, fue posible observar la presencia de terpenos como compuestos principales en el análisis del headspace, así como la actividad antimicrobiana, bacteriostática y bactericida del aceite esencial de hojas secas de $C$. blanchetianus contra las BAL $W$. viridescens y L. mesenteroides.

Palabras clave: Headspace; Antimicrobiano; Bacteriostático; Bactericida.

\section{Introdução}

O Croton blanchetianus é um arbusto colonizador típico do sertão, encontrado em abundância no nordeste brasileiro, popularmente conhecido como marmeleiro (Santos, 2007; Cordeiro et al., 2015). Por ocasião das primeiras chuvas na caatinga, ocorre a floração do marmeleiro, que se caracteriza por apresentar flores pequenas, de cor branca e exalar perfume característico (Silva et al., 2012). As folhas e cascas do gênero Croton, frequentemente espécie C. blanchetianus Baill, são usadas na medicina tradicional, na forma de infusões para distúrbios gastrointestinais, reumatismo, cefaleia, hemoptise e hemorragia uterina (Abreu et al., 2001; Chaves \& Reinhard, 2003; Albuquerque et al., 2007; Cartaxo et al., 2010). Diversas espécies de Croton vêm sendo estudadas e os resultados têm trazido grandes contribuições para o campo científico, como ação antinflamatória, antioxidante e antimicrobiana (Fontenelle, 2008), sendo o C. blanchetianus bastante estudado quanto às potencialidades do seu óleo essencial e extratos (Silva et al., 2020; Silva et al., 2021).

O Croton apresenta uma grande riqueza de metabólitos secundários, compondo o óleo essencial, como alcaloides, terpenos e óleos voláteis. (Araújo et al., 2010; Cavalcanti et al., 2012; Moura et al., 2013; Pereira Jr. et al., 2014). Além de possuir atividades biológicas comprovadas (Silva-Alves et al., 2015). De acordo com Brito et al. (2018), espécies de Croton são uma grande fonte de fitoquímicos com propriedades bioativas excepcionais e sua exploração pode ser útil para diferentes setores industriais, como o de cosméticos, medicinais, farmacêuticos e alimentos.

Dentro do gênero Croton, o C. blanchetianus destaca-se por possuir diferentes propriedades e uma grande aplicabilidade. Firmino et al. (2019) mostraram a atividade antimicrobiana de extratos de C. blanchetianus sobre bactérias comuns na formação de biofilmes orais. A atividade miorrelaxante do óleo essencial de C. blanchetianus sobre o músculo liso da traqueia de ratos foi avaliada, demonstrando o potencial terapêutico no tratamento do broncoespasmo, devido a sua ação broncodilatadora (Pinho-da-Silva et al., 2010). Angélico et al. (2014) reportaram a atividade antimicrobiana de $C$. blanchetianus contra cepas de bactérias Gram-positivas (Bacillus cereus, Staphylococcus aureus) e potencialização de antibióticos (amicacina, canamicina, gentamicina) contra B. cereus, mostrando um efeito sinérgico. Boa atividade antimicrobiana do extrato de marmeleiro sobre linhagens bacterianas causadoras de cárie dentária foi encontrada por Silva et 
al. (2011). Esses autores observaram também que o óleo essencial de C. blanchetianus pode ser utilizado como uma alternativa aos promotores de crescimento, em substituição aos antimicrobianos na ração de frangos de corte, não prejudicando o rendimento de peito de frango. As potencialidades biológicas de C. blanchetianus têm ganhado destaque e suas propriedades já foram avaliadas para aplicação como conservantes de alimentos (Melo, 2011; Ferreira, 2020). Melo et al. (2013) analisaram a eficácia antibacteriana do óleo essencial de $C$. blanchetianus em um modelo de carne cortada em cubos durante o armazenamento sob refrigeração, e concluíram que o óleo essencial de C. blanchetianus é eficaz como agente antimicrobiano in vitro; no entanto, em um sistema modelo usando carne fresca, sua eficácia foi reduzida e, consequentemente, uma concentração maior de óleo essencial foi necessária para inibir o crescimento bacteriano.

A utilização na fase vapor de óleos essenciais foi ressaltada por Pereira et al. (2016), como bons candidatos a atender a busca por novas estratégias de descontaminação, devido a sua ação antimicrobiana. A aplicação do vapor do óleo essencial de carvacrol, orégano, canela, linalol e hortelã-pimenta, bem como o mix destes óleos essenciais, provocaram altas reduções microbianas contra microflora saprófita de mesófilos, enterobactérias e fungos (Botrytis cinerea, Alternaria alternata, Aspergillus niger, Fusarium spp. e Penicillium spp.) e de patógenos (Listeria innocua e L. innocua inoculum), comumente encontrados em ervas culinárias (López-Gómez, et al., 2019). O óleo essencial na fase de vapor pode ser altamente eficaz contra patógenos de origem alimentar e bactérias deteriorantes em concentrações relativamente mais baixas do que na fase líquida, causando assim um efeito mínimo nas propriedades organolépticas (Velázquez-Nuñez et al., 2013).

O uso de compostos voláteis de óleo essencial associado a outras tecnologias, como um sistema de embalagem ativa, através da impregnação de óleo essencial em materiais absorventes, em sachê ou encapsulado, tem sido considerado como aplicações possíveis, destacando o uso potencial na indústria de alimentos (Pola et al., 2016; Paris et al. 2020).

As bactérias ácido lácticas (BAL) são microrganismos Gram-positivos, capazes de crescer em condições microaerófílas e têm crescimento fortemente influenciado pela temperatura. São consideradas os principais microrganismos deteriorantes de produtos cárneos cozidos, embalados a vácuo, mantidos sob refrigeração. Essas bactérias podem causar alterações como sabores estranhos, descoloração, diminuição do pH e produção de limo, levando a perdas para a indústria de alimentos.

Diante do exposto, o presente trabalho tem como objetivo determinar a composição química e atividade antimicrobiana dos compostos voláteis do óleo essencial obtido das folhas secas de C. blanchetianus Baill, sobre as BAL, Weissella viridescens e Leuconostoc mesenteroides, deteriorantes de produtos cárneos.

\section{Metodologia}

\subsection{Material vegetal}

A matéria vegetal foi coletada na Unidade Experimental de Pesquisa e Extensão (UEPE) do Instituto Federal de Educação, Ciência e Tecnologia do Ceará (IFCE), Campus Limoeiro do Norte $\left(05^{\circ} 10825^{\prime}\right.$ S e $38^{\circ} 00717^{\prime}$ O). As coletas foram realizadas no período chuvoso, turno da manhã e identificadas no Herbário Prisco Bezerra, da Universidade Federal do Ceará, onde a exsicata (62200) encontra-se depositada. As folhas de C. blanchetianus foram secas de forma natural, expostas à temperatura ambiente $\left(31 \pm 1{ }^{\circ} \mathrm{C}\right)$, até aproximadamente $9 \%$ de umidade. A determinação do teor de umidade foi realizada segundo procedimento recomendado pelo Instituto Adolfo Lutz (ITAL, 2008).

\subsection{Obtenção do óleo essencial}

A extração do óleo essencial das folhas secas de $C$. blanchetianus Baill foi realizada por meio da técnica de hidrodestilação em aparelho Clevenger modificado (Gottlieb \& Magalhães, 1960), acoplado a um balão de fundo redondo de 
Research, Society and Development, v. 11, n. 1, e28011124785, 2022

5 L e uma manta térmica como fonte geradora de calor, conforme modelo citado na Farmacopeia brasileira (Brasil, 2019). Para cada processo de extração, foram pesados $300 \mathrm{~g}$ da amostra e adicionado de 2,5 L de água destilada e, submetidos a uma temperatura de extração $100{ }^{\circ} \mathrm{C}$, durante 2 horas, contadas a partir do momento da condensação da primeira gota de óleo. Após a extração, o óleo foi coletado e adicionado de, aproximadamente, $5 \mathrm{~g}$ de sulfato de sódio anidro $\left(\mathrm{Na}_{2} \mathrm{SO}_{4}\right)$ para remoção da água residual. A separação do óleo essencial foi feita como auxílio de uma pipeta de Pasteur, que removeu apenas a fase oleosa. O óleo coletado foi acondicionado em frascos de vidro âmbar e armazenado sob refrigeração, até a realização das análises.

\subsection{Determinação dos compostos voláteis}

A análise de compostos voláteis foi realizada por cromatógrafo a gás (Agilent GC 7890A), acoplado ao detector MS Agilent 5975C. A coluna capilar de sílica fundida HP-5MS (Agilent) (30 m de comprimento x $250 \mu \mathrm{m}$ x 0,25 $\mu \mathrm{m}$ de espessura de filme, composta por 5\% de fenil-95\% metilpolissiloxano) foi ligada a um detector triplo quadrupolo e a uma fonte de ionização por Impacto de elétrons (IE), operando em modo positivo a $70 \mathrm{eV}$. A varredura de massa variou de 50 a $550 \mathrm{~m} / \mathrm{z}$. O hélio com grau de pureza 5.0 foi usado como gás de arraste, a fluxo constante de $1,0 \mathrm{~mL} / \mathrm{min}$. As temperaturas do injetor e da interface foram de $250^{\circ} \mathrm{C}$, em modo split de 1:70. Foi utilizado um amostrador automático Agilent GC Sampler 80 equipado com uma seringa de headspace de 2,5 mL. As amostras foram armazenadas em vials de $20 \mathrm{~mL}$ e incubadas à temperatura $\mathrm{e}$ tempo de $80{ }^{\circ} \mathrm{C}$ e $300 \mathrm{~s}$, respectivamente. A temperatura da seringa foi de $100{ }^{\circ} \mathrm{C}$ e a velocidade do Agitador de $500 \mathrm{rpm} . \mathrm{O}$ volume de injeção foi de $250 \mu$ l. O programa de temperatura do forno consistiu em uma temperatura inicial de $70{ }^{\circ} \mathrm{C}$, aquecido a $4{ }^{\circ} \mathrm{C} / \mathrm{min}$ até $180^{\circ} \mathrm{C}$ e então $10^{\circ} \mathrm{C} / \mathrm{min}$ até $250{ }^{\circ} \mathrm{C}$. Os compostos foram identificados comparando seus espectros de massa com os do banco de dados do Instituto Nacional de Padrões e Tecnologia (NIST, 2011).

\subsection{Determinação da Dose Mínima Inibitória (DMI) da fase vapor}

A Dose Mínima Inibitória (DMI) da fase vapor foi determinada conforme o método de Almeida (2017), com modificações. As cepas das bactérias ácido-lácticas (BAL) W. viridescens ATCC 12706 e L. mesenteroides ATCC 8293 foram adquiridas na forma liofilizada e reidratadas em caldo De Man, Rogosa e Sharpe (MRS), pH 6,5 (Difco ${ }^{\mathrm{TM}}$, Detroit, EUA), em seguida foram armazenadas a $-20{ }^{\circ} \mathrm{C}$, em microtubos (volume do microtubo) com caldo MRS contendo $20 \%$ (v/v) de glicerol. Para o preparo do pré-inóculo, as BAL foram reativadas, individualmente, em $10 \mathrm{~mL}$ de caldo MRS (Difco ${ }^{\mathrm{TM}}$, Detroit, EUA) e incubadas a $30{ }^{\circ} \mathrm{C}$, em BOD (TECNAL modelo TE 390), por 18 horas (baseado em estudo prévio do grupo). A partir do inóculo $\left(10^{9} \mathrm{UFC} / \mathrm{mL}\right)$ das BAL, foram preparadas as diluições em série em água peptonada $0,1 \%$, até uma concentração de $10^{4} \mathrm{UFC} / \mathrm{mL}$. Adicionou-se $100 \mu \mathrm{L}$ de cada suspenção bacteriana em pontos específicos na superfície do Ágar MRS (Difco ${ }^{\mathrm{TM}}$, Detroit, EUA) para a determinação visual do crescimento microbiano. Papeis de filtro circulares, com a mesma área da superfície interna da tampa de placa de Petri (aproximadamente $63 \mathrm{~cm}^{2}$ ) e previamente esterilizados, foram adicionados de 100 $\mu \mathrm{L}$ das concentrações testadas de $0,90 \mathrm{~g} / \mathrm{mL}$ do óleo essencial e soluções de óleo essencial em DMSO 5\% (v/v) de 0,81, 0,73, 0,65, 0,57, 0,40, 0,32, 0,24, 0,16, 0,08 mg/mL. Os papéis de filtro impregnados com as soluções de óleo essencial de $C$. blanchetianus foram colocados na tampa das placas de Petri, que foram fechadas e com suas bordas seladas com parafilme (parafilm $\mathrm{M} ®$ ). Todas as concentrações testadas foram realizadas em duplicata e foram feitos dois controles, sendo um colocando somente o DMSO 5\% no papel de filtro estéril e outro controle foi com o uso somente de papel de filtro estéril na tampa da placa de Petri. Posteriormente todas as placas de Petri foram incubadas invertidas na BOD (TECNAL modelo TE 390) a $30^{\circ} \mathrm{C}$ por 48 horas.

A dose mínima inibitória (DMI) foi definida como a dose mínima de solução de óleo essencial de C. blanchetianus 
em DMSO 5\% necessária para inibir completamente o crescimento de bactérias durante 48 horas. Os resultados foram baseados na presença ou ausência de crescimento, sendo avaliados visualmente. Após a determinação do DIM, foi retirado o papel de filtro com solução de óleo essencial de C. blanchetianus em DMSO 5\% das placas de Petri em que não foi observado crescimento bacteriano aparente, para verificar se, na fase vapor, as soluções de óleo essencial de C. blanchetianus em DMSO $5 \%$ testadas apresentaram efeito bactericida (sem crescimento após a retirada do papel de filtro) ou bacteriostático (com crescimento após a retirada do papel de filtro). A borda dessas placas de Petri foi selada com Parafilm M® e posteriormente incubadas invertidas na BOD (TECNAL modelo TE 390) $30{ }^{\circ} \mathrm{C}$ durante 48 horas.

\section{Resultados e Discussão}

\subsection{Compostos voláteis}

A Tabela 1 mostra a área relativa (AR = área do composto: área total) correspondente à porcentagem dos compostos voláteis do óleo essencial das folhas secas de C. blanchetianus, determinada pela técnica de headspace. A análise dos compostos voláteis revelou a presença de 27 compostos, sendo 2 majoritários, Eucaliptol (32,94\%) e D- $\alpha$-Pineno (29,43\%) (Tabela 1). Esses compostos são da classe química dos terpenos (monoterpenos) e caracterizados por possuírem baixa massa molecular (Bakkali, et al, 2008). Segundo Angélico et al. (2011), na análise do óleo essencial das folhas frescas do C. blanchetianuas, Eucaliptol e D- $\alpha$-Pineno foram encontrados como compostos voláteis do óleo estudado, similares aos resultados obtidos no presente estudo. Normalmente, os compostos majoritários determinam as propriedades biológicas do óleo essencial (Bakkali et al. 2008).

Tabela 1 - Área relativa (AR) correspondente à porcentagem dos compostos voláteis do óleo essencial das folhas secas de

Croton blanchetianus determinada por headspace.

\begin{tabular}{|c|c|c|c|}
\hline $\mathrm{N}^{\mathrm{o}}$ & Compostos voláteis & $\mathrm{RT}^{*}$ & $\mathrm{AR}$ \\
\hline 1 & 2-Borneno & 3,7721 & 0,0579 \\
\hline 2 & Biciclo [3.1.0] hex-2-eno, 4-metil-1- (1-metiletil) -- & 4,0812 & 3,5903 \\
\hline 3 & D- $\alpha$-Pineno & 4,2242 & 29,4331 \\
\hline 4 & Biciclo [2.2.1] heptano, 2,2-dimetil-3-metileno-, (1S) -- & 4,4874 & 0,3434 \\
\hline 5 & $\beta$-Felandrene & 4,8937 & 5,271 \\
\hline 6 & $\beta$-Pineno & 4,9852 & 2,6393 \\
\hline 7 & Biciclo [3.1.0] hex-2-eno, 4-metil-1- (1-metiletil) - & 5,1512 & 8,3497 \\
\hline 8 & Terpinoleno & 5,4144 & 0,0895 \\
\hline 9 & B-Pinene & 5,483 & 0,3307 \\
\hline 10 & 3-Carene & 5,6204 & 0,5204 \\
\hline 11 & o-Cymene & 5,9122 & 3,6221 \\
\hline 12 & D-Limonene & 6,0152 & 7,1367 \\
\hline 13 & Eucaliptol & 6,0838 & 32,9493 \\
\hline 14 & Z-Ocimene & 6,3985 & 0,1623 \\
\hline 15 & Hidrato de Sabinene <cis-> & 6,9021 & 0,4081 \\
\hline 16 & Terpinoleno & 7,4514 & 0,2213 \\
\hline 17 & $\gamma$-terpineno & 7,686 & 0,4998 \\
\hline 18 & Álcool fenquílico & 8,1151 & 0,175 \\
\hline 19 & $\gamma$-Terpineno & 9,9061 & 0,3869 \\
\hline 20 & $\alpha$. -Terpineol & 10,278 & 0,3598 \\
\hline
\end{tabular}


Research, Society and Development, v. 11, n. 1, e28011124785, 2022 (CC BY 4.0) | ISSN 2525-3409 | DOI: http://dx.doi.org/10.33448/rsd-v11i1.24785

\begin{tabular}{|c|c|c|c|}
\hline 21 & Copena & 15,9599 & 0,1308 \\
\hline 22 & $\beta$-Bourbonene & 16,2461 & 0,1043 \\
\hline 23 & $\alpha$ selineno & 16,4978 & 1,0316 \\
\hline 24 & Cariofileno & 17,2989 & 1,5178 \\
\hline 25 & Aromadendreno & 17,8825 & 0,1432 \\
\hline 26 & 1,4,7, -Cicloundecatrieno, 1,5,9,9-tetrametil-, Z, Z, Z-- & 18,3174 & 0,1715 \\
\hline 27 & Biciclogermacreno & 19,5934 & 0,3542 \\
\hline Total & & & 100 \\
\hline
\end{tabular}

RT* - Tempo de retenção. Fonte: Autores.

Os monoterpenos constituem 90\% dos óleos essenciais. São altamente hidrofóbicos e seus efeitos biológicos estão relacionados com interações com a membrana dos microrganismos. Possuem aplicabilidade diversa, comumente utilizados como componentes de fragrâncias, cosméticos, produtos de limpeza, desinfetantes, aditivos de alimentos e remédios devido aos aromas e possuem relevantes propriedades antimicrobianas (Toscan, 2010). As características dos vapores dos óleos essências são determinadas por seus componentes e suas volatilidades relativas, apresentando um impacto no potencial antimicrobiano (Burt, 2004).

Segundo Martins et al. (2019), o eucaliptol constituiu o principal componente do óleo essencial de Lavandula dentata L. e a presença desse pode conferir propriedades medicinais ao óleo essencial, devido à ação antifúngica. Através da análise in sílico, Gomes et al. (2020) observaram o baixo potencial toxicológico do monoterpeno eucaliptol, e que a molécula não apresentou potencial mutagênico e carcinogênico, tornando assim a substância viável para uso terapêutico, de forma eficaz e segura considerando-se os efeitos colaterais no organismo. Ainda Martínez-Pabón et al. (2020) destacaram o composto eucaliptol como um agente com atividade antimicrobiana de amplo espectro, com efeito sobre microrganismos ligados a doenças bucais.

O composto $\alpha$-pineno é um dos compostos majoritários presente em alguns óleos essenciais, como por exemplo o das folhas de Libanothamnus neriifolius, Psidium guajava L., com atividade antimicrobiana e destacam-se como fontes promissoras de agentes naturais antimicrobianos (Aparicio-Zambrano et al., 2019; Trindade et al., 2021). Zamyad et al. (2019) sugerem que $\alpha$-pineno, pelo menos em parte, é responsável pela indução dos efeitos anticonvulsivantes e antioxidantes do óleo essencial de Ducrosia anethifolia em ratos. No estudo do potencial antimicrobiano do $\alpha$-pineno, foi verificada a ação antibacteriana frente às cepas de Streptococcus mutans e Escherichia coli (Costa, 2017).

\subsection{Dose Mínima Inibitória (DMI) na fase vapor}

A Tabela 2 apresenta, de forma qualitativa, o resultado do efeito dos compostos voláteis do óleo essencial de $C$. blanchetianus sobre o crescimento de W. viridescens e L. mesenteroides. A Dose Mínima Inibitória (DMI) para ambos os microrganismos estudados foi de $0,32 \mathrm{~g} / \mathrm{mL}$, ou seja, após 48 horas de incubação a $30{ }^{\circ} \mathrm{C}$, não foi observado crescimento microbiano nas respectivas placas contendo essa concentração de óleo essencial no papel filtro colocado na tampa da placa. 
Research, Society and Development, v. 11, n. 1, e28011124785, 2022

(CC BY 4.0) | ISSN 2525-3409 | DOI: http://dx.doi.org/10.33448/rsd-v11i1.24785

Tabela 2 - Avaliação visual do efeito dos compostos voláteis de diferentes concentrações do óleo essencial de $C$.

blanchetianus sobre o crescimento de W. viridescens e L. mesenteroides.

\begin{tabular}{ccc}
\hline \multirow{2}{*}{ Concentração testada $(\mathrm{g} / \mathrm{mL})$} & \multicolumn{2}{c}{ Cepas } \\
\cline { 2 - 3 } & W. viridescens & L. mesenteroides \\
\hline 0,90 & $*$ & $*$ \\
0,81 & $*$ & $*$ \\
0,73 & $*$ & $*$ \\
0,65 & $*$ & $*$ \\
0,57 & $*$ & $*$ \\
0,40 & $*$ & $*$ \\
0,32 & $*$ & $*$ \\
0,24 & $* *$ & $* *$ \\
0,16 & $* *$ & $* *$ \\
0,08 & $* *$ & $* *$ \\
Controle & $* *$ & $* *$ \\
\hline
\end{tabular}

(*) Sem Crescimento, (**) Crescimento. Fonte: Autores.

Após a determinação da DIM, foram removidos os papéis de filtro das amostras que não apresentaram crescimento microbiano durante as 48 horas de incubação a $30^{\circ} \mathrm{C}$. Em seguida, as placas foram reincubadas nas mesmas condições de tempo e temperatura anteriormente citadas, para avaliação do efeito bacteriostático ou bactericida.

Os compostos voláteis do óleo essencial de C. blanchetianus apresentaram efeito bactericida (sem crescimento) para $W$. viridescens na concentração de óleo de $0,32 \mathrm{~g} / \mathrm{mL}$ (a massa adicionada equivale a $32 \mathrm{mg}$ de óleo por placa de Petri) e com 0,57 g/mL (57 mg por placa de Petri) para L. mesenteroides. O efeito bacteriostático foi observado apenas para $L$. mesenteroides, cujo crescimento foi observado no meio utilizando a concentração de 0,57 g/mL, indicando atividade bacteriostática dos compostos voláteis do óleo em estudo contra esta bactéria. Com base nos resultados obtidos, pode-se afirmar que a bactéria $W$. viridescens mostrou-se mais sensível à ação do óleo essencial de C. blanchetianus.

Uma das características que os óleos essenciais apresentam é sua volatilidade (Burt, 2004; Simões, 2011). A hidrofocidade também é um fator importante, de acordo com Ben Arfa et al. (2006) no estudo da atividade antimicrobiana do carvacrol, constataram que a característica hidrofóbica permite o acúmulo de composto na membrana e graças a sua hidrofobicidade apropriada, o carvacrol pode ser acumulado na membrana celular, e induzir uma modificação conformacional na mesma resultando na morte celular microbiana. Desta forma pode-se inferir que os componentes voláteis majoritários do óleo essencial de C. blanchetianus foram responsáveis pelo efeito bacteriostático e bactericida apresentado contra as bactérias W. viridescens e L. mesenteroides.

Avaliando a atividade antimicrobiana do vapor do óleo essencial de orégano (Origanum vulgare) (OEO), Paganini (2017) utilizou metodologia semelhando ao presente trabalho. A dose mínima inibitória dos compostos voláteis do OEO observada para $W$. viridescens e P. fluorescens foi de 13,8 e 18,4 mg de óleo essencial de orégano por placa de Petri, respectivamente. Avaliando o efeito bacteriostático e bactericida, apenas $P$. fluorescens apresentou efeito bacteriostático e efeito bactericida sobre W. viridescens. A BAL estudada também foi mais sensível ao óleo, como no presente estudo.

Paganini et al. (2021) aplicou filmes de acetato de celulose (AC) incorporados com OEO para inibir o crescimento de bactérias associadas à deterioração de produtos cárneos (W. viridescens (microaerofílica) e P. fluorescens (aeróbia)). A 
Research, Society and Development, v. 11, n. 1, e28011124785, 2022

(CC BY 4.0) | ISSN 2525-3409 | DOI: http://dx.doi.org/10.33448/rsd-v11i1.24785

atividade antimicrobiana em fase vapor dos filmes contendo OEO foi determinada, mostrando melhor efeito antimicrobiano contra $W$. viridescens do que $P$. fluorescens. A aplicação do filme incorporado com $75 \mathrm{mg}$ de OEO levou a inibição total do crescimento de $W$. viridescens, enquanto para $P$. fluorescens ocorreu apenas a inibição de uma parcela da população bacteriana.

\section{Conclusão}

A análise dos compostos voláteis do óleo essencial das folhas secas de C. blanchetianus por headspace, mostrou que os terpenos eucaliptol $(32,94 \%)$ e D- $\alpha$-pineno $(29,43 \%)$ são os compostos majoritários.

Os resultados mostraram relevante atividade antimicrobiana dos compostos voláteis do óleo essencial das folhas secas de $C$. blanchetianus contra as duas bactérias estudadas. O efeito bactericida foi observado para uma concentração de óleo de $0,32 \mathrm{~g} / \mathrm{mL}$ e $0,57 \mathrm{~g} / \mathrm{mL}$ para $W$. viridescens e L. mesenteroides, respectivamente. O óleo essencial apresentou efeito bacteriostático apenas para L. mesenteroides com solução de $0,57 \mathrm{~g} / \mathrm{mL}$. Portanto, a bactéria $W$. viridescens se mostrou mais sensível à ação antimicrobiana do óleo.

Os resultados obtidos no presente estudo demostram que os compostos voláteis do óleo essencial de C. blanchetianus apresentam atividade antimicrobiana contra importantes bactérias responsáveis pela deterioração de produtos cárneos. Pesquisas futuras podem se concentrar na análise da eficácia potencial dos compostos voláteis desse óleo em embalagens ativas para alimentos.

\section{Agradecimentos}

Os autores agradecem a Coordenação de Aperfeiçoamento de Pessoal de Nível Superior (CAPES)/Doutorado Institucional (DINTER), ao Instituto Federal do Ceará (IFCE), a Universidade Federal de Santa Catarina (UFSC), ao Laboratório Integrado de Engenharia Biológica (Lieb) e a Central de Análise da UFSC.

\section{Referências}

Abreu, A. S., Barbosa, P. S., Müller, A. H. \& Guilhon, G. S. P. (2001). Constituintes químicos do caule e das cascas do caule de Croton pullei var. Glabrior (Euphorbiaceae). Revista Virtual de Iniciação Acadêmica da UFPA, 1(2), 1-9. http://www.ufpa.br/revistaic.

Albuquerque, U. P., Medeiros, P. N., Almeida, A. L. S., Monteiro, J. M., Neto, E. M. F., Melo, J. G. \& Santos, J. P. (2007). Medicinal plants of the caatinga (semi-arid) vegetation of NE Brazil: a quantitative approach. Journal of Ethnopharmacology, 114(3), 325-354. doi:10.1016/j.jep.2007.08.017

Almeida, P. P. (2017). Desenvolvimento de sistema de embalagem ativo antimicrobiano para pães de forma. Tese (Doutorado em Engenharia de Alimentos) Universidade Federal de Santa Catarina, Florianópolis, SC, 202p.

Angélico, E. C., Costa, J. G. M., Rodrigues, O. G, Lima, E. Q. \& Medeiros, R. S. (2011). Composição química do óleo essencial das folhas de Croton blanchetianus (Baill): Resultados preliminares. Revista da Biologia e Farmácia, 5(2), 44-49.

Angélico, E. C., Onaldo; G. R., Costa, J. G. M., Lucena, M. F. A., Queiroga Neto, V. \& Medeiros, R. S. (2014). Chemical characterization and antimicrobial activity of essential oils and Croton's varieties modulator in the Brazilian's Northeast Semiarid. African Journal of Plant Science, 8(7), 392-397. doi:10.5897/AJPS2014.1198

Aparicio-Zambrano, R., Rojas-Fermín, L. Velasco, J., Usubillaga, A., Sosa, M. \& Rojas, J. (2019). Caracterización química y actividad antimicrobiana del aceite esencial de las hojas de Libanothamnus neriifolius (Asteraceae). Revista peruana de biología, 26(1), 95-100. doi:10.15381/rpb.v26i1.15912

Araújo, K. D., Parente, H. N., Éder-Silva, É., Ramalho, C. I., Dantas, R. T., Andrade, L. P. \& Silva, D. S. (2010). Levantamento florístico do estrato arbustivo arbóreo em áreas contíguas de Caatinga no Cariri Paraibano. Revista Caatinga, 23(1), 63-70, 2010.

Bakkali, F., Averbeck, S., Averbeck, D. \& Idaomar, M. (2008). Biological effects of essential oils - A review. Food and Chemical Toxicology, 46, 446-475.

Ben Arfa, A., Combes, S., Preziosi-Belloy, L., Gontard, N. \& Chalier, P. (2006). Antimicrobial activity of carvacrol related to its chemical structure. Letters in Applied Microbiology, 43, 149-154. doi:10.1111/j.1472-765X.2006.01938.x

Burt, S. (2004). Essential oils: their antibacterial properties and potential applications in foods — a review. International Journal of Food Microbiology, 94, 223-253. doi:10.1016/j.ijfoodmicro.2004.03.022 
Research, Society and Development, v. 11, n. 1, e28011124785, 2022 (CC BY 4.0) | ISSN 2525-3409 | DOI: http://dx.doi.org/10.33448/rsd-v11i1.24785

BRASIL. (2019). Farmacopeia Brasileira. Agência Nacional de Vigilância Sanitária (6a ed., 874 p). Brasília (DF): Agência Nacional de Vigilância Sanitária.

Brito, S. S. S., Silva, F., Malheiro, R., Baptista, P. \& Pereira, J. A. A. (2018). Croton argyrophyllus Kunth and Croton heliotropiifolius Kunth: Phytochemical characterization and bioactive properties. Industrial Crops \& Products, 113, 308-315. doi:10.1016/j.indcrop.2018.01.044

Cartaxo, A. L., Souza, M. M. A. \& Albuquerque, U. P. (2010). Medicinal plants with bioprospecting potential used in semi-arid northeastern Brazil. Journal of Ethnopharmacology, 131, 326-342. doi:10.1016/j.jep.2010.07.003

Cavalcanti, J. M., Leal-Cardoso, J. H., Diniz, L. R. L., Portella, V. G., Costa, C. O., Linard, C. F. B. M., Alves, K., Rocha, M. V. A. P., Lima, C. C., Cecatto, V. M. \& Coelho-de-Souza, A. N. (2012). The essential oil of Croton zehntneri and trans-anethole improves cutaneous wound healing. Ethnopharmacol, 144(2), 240-247. doi:10.1016/j.jep.2012.08.030

Chaves, S. A. M. \& Reinhard, K. J. (2003). Palespharmacology and Pollen: Theory, Method and Application, Memoirs Intitute de Oswaldo Cruz. 98, (Suppl). 207-211.

Cordeiro, I., Secco, R., Carneiro-Torres, D.S., Lima, L.R., Caruzo, M. B. R., Berry, P., Riina, R., Silva, O. L. M., Silva, M. J. \& Sodré, R. C. (2015). Croton in Lista de Espécies da Flora do Brasil. Jardim Botânico do Rio de Janeiro. http://floradobrasil.jbrj.gov.br/jabot/floradobrasil/FB25478.

Costa, D. F. N. (2017). Potencial imunomodulador e antimicrobiano do (+)- $\alpha$-pineno e (+)- $\beta$-pineno. Dissertação (Mestre em odontologia) - Universidade Federal da Paraíba, João Pessoa, PB, 53p.

Ferreira, M. J. G., Dias, F. G. B., Santos, S. M., Menezes, R. C. S., Silva, L. M. R. \& Figueiredo, E. A. T. (2020). Avaliação de plantas medicinais como potenciais aditivos antimicrobianos alimentares. Research, Society and Development, 9(5), 1-14. doi:10.33448/rsd-v9i5.3295

Firmino, N. C. S., Alexandre, F. S. O., Vasconcelos, M. A., Pinheiro, A. A., Arruda, F. V. S., Guedes, M. L. S., Silveira, E. R. \& Teixeira, E. H. (2019). Diterpenes isolated from Croton blanchetianus Baill: Potential compounds in prevention and control of the oral Streptococci biofilms. Industrial Crops \& Products, 131,371-377. doi:10.1016/j.indcrop.2019.01.062

Fontenelle, R. O. S. (2008). Efeito antifúngico de óleos essenciais de Lippia sidoides Cham., Croton argyrophylloides Muell., Croton zenhtneri Pax et Hoffm., Croton nepetaefolius Baill. e de seus principais constituintes contra dermatófitos e Candida spp. Isolados de cães. Tese (Doutorado no Programa de PósGraduação em Ciências Veterinárias) - Universidade Estadual do Ceará, Fortaleza, CE, 163p.

Gomes, L. L., Araújo Neto, A. P., Medeiros, F. L. S., Santana, M. T. P., Santos, T. A., Oliveira, H. M. B. F. \& Guênes, G. M. T. (2020). Análise in silico da toxicidade do monoterpeno eucaliptol. Research, Society and Development, 9(5), 1-11. doi: 10.33448/rsd-v9i5.3092

Gottlieb, O. R. \& Magalhães, M. T. (1960). Modified distillation trap. Chemist Analyst (4nd ed., p. 49-114), 1960.

ITAL- Instituto Adolfo Lutz. (2008). Métodos físico-químicos para análise de alimentos (4a ed.). São Paulo: Instituto Adolfo Lutz.

López-Gómez, A., Ros-Chumillas, M., Antolinos, V., Buendía-Moreno, L., Navarro-Segura, L., Sánchez-Martínez,M. J., Martínez-Hernández, G. B. \& SotoJover, S. (2019). Fresh culinary herbs decontamination with essential oil vapours applied under vacuum conditions. Postharvest Biology and Technology, 156, 1-8. doi: 10.1016/j.postharvbio.2019.110942

Martínez-Pabón, M. C. \& Ortega-Cuadros, M. (2020). Thymol, menthol and eucalyptol as agents for microbiological control on the cavity. A scoping review. Rev. Colomb. Cienc. Quím. Farm. 49(1), 44-69. doi: 10.15446/rcciquifa.v49n1.87006

Martins, R. P., Gomes, R. A. S.., Malpass, A. C. G. \& Okura, M. H. (2019). Chemical characterization of Lavandula dentata L. essential oils grown in Uberaba-MG. Ciência Rural, 49(8), 1-7. doi: 10.1590/0103-8478cr20180964

Melo, G. F. A. (2011). Estudo da composição química e da atividade antibacterina in vitro e em alimentos do óleo essencial de Croton blanchetianus Baill. Dissertação (Mestrado em Ciências e Tecnologia de Alimentos) - Universidade Federal da Paraíba. João Pessoa, PB, 94p.

Melo, G. F. A., Costa, A. C. V., Garino Jr. F., Medeiros, R. S., Madruga, M. S. \& Queiroga Neto, V. (2013). The sensitivity of bacterial foodborne pathogens to Croton blanchetianus Baill essential oil. Brazilian Journal of Microbiology, 44(4), 1189-1194.

Moura, F. M. L., Baptista, R. I. A. A., Santos, V. V. M., Moura, A. P. B. L. \& Costa, M. M. (2013). Utilização de plantas do bioma caatinga no controle de patógenos de interesse na área de alimentos - uma revisão. Acta Veterinária Brasílica, 7(2), 125- 136.

NIST (National Institute of Standards and Technology). (2011). Mass $\quad$ Spectrometry Data Center. https://www.nist.gov/system/files/documents/srd/NIST1a11Ver2-0Man.pdf. https://chemdata.nist.gov.

Paganini, C. C. (2017). Ação Antimicrobiana de filme ativo incorporado com óleo essencial de orégano no crescimento de Weissella viridescens e Pseudomonas fluorescens. Dissertação (Mestrado em engenharia de alimentos) - Universidade Federal de Santa Catarina, Florianópolis, SC, 84p.

Paganini, C. C., Laroque, D. A., Carciofi, B. A. M. \& Aragão, G. M. F. (2021). Shelf-life extension of meat products by cellulose acetate antimicrobial film incorporated with oregano's essential oil. Research, Society and Development, 10(16), 1-12. doi: 10.33448/rsd-v10i16.23335

Paris, M. J., Ramírez-Corona, N., Palou, E. \& López-Malo. (2020). Modelling release mechanisms of cinnamon (Cinnamomum zeylanicum) essential oil encapsulated in alginate beads during vapor-phase application. Journal of Food Engineering, 282, 1-9. doi:10.1016/j.jfoodeng.2020.110024

Pereira, M. A. A. (2016). Determinação da atividade antimicrobiana na fase vapor do óleo essencial Hesperozygis mirtoides (St. Hiy ex. Benth.) Epling. Tese (Doutorado em farmácia) - Universidade de São Paulo, São Paulo, SP, 96p.

Pereira Jr, L. R., Andrade, A. P., Araújo, K. D., Barbosa, A. S. \& Barbosa, F. M. B. (2014). Espécies da Caatinga como alternativa para o desenvolvimento de novos fitofármacos. Floresta e Ambiente, 21(4), 509-520. doi:10.1590/2179-8087.024212 
Research, Society and Development, v. 11, n. 1, e28011124785, 2022 (CC BY 4.0) | ISSN 2525-3409 | DOI: http://dx.doi.org/10.33448/rsd-v11i1.24785

Pinho-da-Silva, L., Mendes-Maia, P. V., Garcia, T. M. N., Cruz, J. S., Morais, S. M., Coelho-de-Souza, A. N., Lahlou, S. \& Leal-Cardoso, J. H. (2010). Croton sonderianus essential oil samples distinctly affect rat airway smooth muscle. Phytomedicine, 17, 721-725. doi:10.1016/j.phymed.2010.01.015

Pola, C. C., Medeiros, E. A.A. Pereira, O. L., Souza, V. G. L., Otoni, C. G., Camilloto, G. P. \& Soares, N. F. F. (2016). Cellulose acetate active films incorporated with oregano (Origanum vulgare) essential oil and organophilic montmorillonite clay control the growth of phytopathogenic fungi. Food Packaging and Shelf Life, 9, 69-78. .doi:10.1016/j.fps1.2016.07.001

Santos, C. C. (2007). Contribuição ao conhecimento químico de plantas do Nordeste do Brasil: Erthroxylum barbatum O.E. Schulz, Erythroxylum amplifolium (Mart) O.E. Schulz (Erythoxylaceae) e Croton sonderianus Muell. Arg. (Euphorbiaceae). Tese (Doutorado em Química orgânica) - Universidade Federal do Ceará, Fortaleza, CE, 306p.

Silva, V. A., Oliveira, C. R. M., Freitas, A. F. R., Costa, M. R. M., Pessoa, H. L. F. \& Pereira, M. S. V. (2011). Eficácia antimicrobiana do extrato do Croton sonderianus Müll. sobre bactérias causadoras da cárie dentária. Revista de Odontologia da UNESP, 40(2), 69-72.

Silva, A. B., Oliveira, C. R. F., Matos, C. H. C., Santos, P. É. M. \& Lira, C. R. I. M. (2020). Bioatividade do óleo essencial de Croton blanchetianus Baill (Euphorbiaceae) sobre Callosobruchus maculatus Fabricius, 1775 (Coleoptera: Chrysomelidae). Nativa, Sinop, 8(4), 450-455. doi:10.31413/nativa.v8i4.8456

Silva, A. I. B., Sá-Filho, G. F., Oliveira, L. C., Guzen, F. P., Cavalcanti, J. R. L. P. \& Cavalcanti, J. S. (2021). Perfil fitoquímico de extratos etanólicos e metanólicos do Croaton blanchetianus. Revista Brasileira multidisciplinar, 24(1), 134-142. doi:10.25061/2527-2675/ReBraM/2021.v24i1.1057

Silva, C. M., Silva, C. I., Hrncir, M., Queiroz, R. T. \& Fonseca. (2012). Guia de plantas: visitadas pelas abelhas na Caatinga (V. L. I.). Fortaleza: Editora Fundação Brasil Cidadão.

Silva-Alves, K. S., Silva, F. W. F., Souza, A. N. C., Albuquerque, A. A. C.; Vale, O. C. \& Leal-Cardoso, J. H. (2015). Essential oil of Croton zehntneri and its main constituent anethole block excitability of rat peripheral nerve. Planta Med, 81(4), 292-297. doi:10.1055/s-0034-1396309

Simões, C. M. O., Schenkel, E. P., Mello, J. C. P., Mentz, L. A. \& Petrovick, P. R. (2011). Farmacognosia: da planta ao medicamento (6a ed.). Porto Alegre: Universidade Federal de Santa Catarina - UFSC.

Toscan, C. M. (2010). Atividade antimicrobiana e antioxidante de terpenoides. Dissertação (Mestrado em Biotecnologia) - Universidade de Caxias do Sul. Caxias do Sul, RS, 84p.

Trindade, J. K. M., Trindade, I. T. M. Abegg, M. A., Corrêa, G. M., Carmo \& D. F. M. (2021). Perfil químico e atividade antimicrobiana do óleo essencial de variedades de Psidium guajava L. (Myrtaceae). Research, Society and Development, 10(10), 1-11. doi:10.33448/rsd-v10i10.18794

Velázquez-Nuñez, M. J., Avila-Sosa, R., Palou, E. \& López-Malo, A. (2013). Antifungal activity of orange (Citrus sinensis var. Valencia) peel essential oil applied by direct addition or vapor contact. Food Control, 31, 1-4. doi: 10.1016/j.foodcont.2012.09.029

Zamyad, M., Abbasnejad, M. Esmaeili-Mahani, S., Mostafavi, A. \& Sheibani, V. (2019). The anticonvulsant effects of Ducrosia anethifolia (Boiss) essential oil are produced by its main component alpha-pinene in rats. Arq Neuropsiquiatr, 77(2), 106-114. doi:10.1590/0004-282X20180147 